\title{
Successful weight loss maintenance includes long-term increased meal responses of GLP-1 and PYY
}

\author{
Eva W lepsen ${ }^{1,2}$, Julie Lundgren ${ }^{1,2}$, Jens J Holst ${ }^{1,2}$, Sten Madsbad ${ }^{3}$ and \\ Signe S Torekov ${ }^{1,2}$ \\ ${ }^{1}$ Department of Biomedical Sciences, Faculty of Health and Medical Sciences, University of Copenhagen, \\ Copenhagen, Denmark, ${ }^{2}$ The Novo Nordisk Foundation Center for Basic Metabolic Research, \\ Faculty of Health and Medical Sciences, University of Copenhagen, Copenhagen, Denmark, and \\ ${ }^{3}$ Department of Endocrinology, Hvidovre University Hospital, Hvidovre, Denmark
}

Correspondence should be addressed to S S Torekov

Email

torekov@sund.ku.dk

\begin{abstract}
Objective: The hormones glucagon-like peptide 1 (GLP-1), peptide $Y_{3-36}\left(P Y_{3-36}\right)$, ghrelin, glucose-dependent insulinotropic polypeptide (GIP) and glucagon have all been implicated in the pathogenesis of obesity. However, it is unknown whether they exhibit adaptive changes with respect to postprandial secretion to a sustained weight loss. Design: The study was designed as a longitudinal prospective intervention study with data obtained at baseline, after 8 weeks of weight loss and 1 year after weight loss.

Methods: Twenty healthy obese individuals obtained a $13 \%$ weight loss by adhering to an 8 -week very low-calorie diet $(800 \mathrm{kcal} / \mathrm{day})$. After weight loss, participants entered a 52-week weight maintenance protocol. Plasma levels of GLP-1, PYY ${ }_{3-36}$, ghrelin, GIP and glucagon during a 600-kcal meal were measured before weight loss, after weight loss and after 1 year of weight maintenance. Area under the curve (AUC) was calculated as total AUC (tAUC) and incremental AUC (iAUC).

Results: Weight loss was successfully maintained for 52 weeks. iAUC for GLP-1 increased by $44 \%$ after weight loss $(P<0.04)$ and increased to $72 \%$ at week $52(P=0.0001)$. iAUC for $P Y Y_{3-36}$ increased by $74 \%$ after weight loss $(P<0.0001)$ and by $36 \%$ at week $52(P=0.02)$. tAUC for ghrelin increased by $23 \%$ after weight loss $(P<0.0001)$, but at week 52 , the increase was reduced to $16 \%$ compared with before weight loss $(P=0.005)$. iAUC for GIP increased by $36 \%$ after weight loss $(P=0.001)$, but returned to before weight loss levels at week 52 . Glucagon levels were unaffected by weight loss.

Conclusions: Meal responses of GLP-1 and PYY ${ }_{3-36}$ remained increased 1 year after weight maintenance, whereas ghrelin and GIP reverted toward before-weight loss values. Thus, an increase in appetite inhibitory mechanisms and a partly decrease in appetite-stimulating mechanisms appear to contribute to successful long-term weight loss maintenance.

European Journal of Endocrinology (2016) 174, 775-784
\end{abstract}

\section{Introduction}

Weight regain after weight loss represents an unsolved challenge $(1,2)$. Thus, identification of hormonal changes associated with maintained weight loss is important as they may support or counteract successful long-term weight loss maintenance. The gut-derived incretin hormone, glucagon-like peptide 1 (GLP-1), may together with peptide $\mathrm{YY}_{3-36}\left(\mathrm{PYY}_{3-36}\right)$ - be a key mediator (c) 2016 European Society of Endocrinology Printed in Great Britain in postmeal satiety and thus the limitation of energy intake (3). The effect involves both peripheral and central mechanisms $(4,5)$. The postprandial GLP-1 response is attenuated in obese individuals $(6,7,8)$, and recent studies have indicated that the impairment may be an early feature of obesity, as low GLP-1 responses are seen in overweight people independent of glucose tolerance

Published by Bioscientifica Ltd. 
status (9). In obesity, an inverse relationship between postprandial GLP-1 and insulin levels has been proposed, suggesting that insulin resistance may promote further weight gain through an impaired GLP-1 response (7). The observations regarding the effect of weight reduction on meal-induced GLP-1 responses in obesity are mainly derived from studies of obese subjects investigated after bariatric surgery, showing that postprandial GLP-1 levels are higher after Roux-en-Y gastric bypass (RYGB) than after laparoscopic assisted gastric bypass $(10,11)$. This observation may in part explain the higher degree of weight loss in RYGB compared with adjustable gastric banding patients (12). The secretory GLP-1 response to a meal after long-term weight reduction (up to a year) is unknown, and only few studies have examined the acute effect of diet-induced weight loss on basal and postprandial GLP-1 levels. Verdich et al. demonstrated an attenuated postprandial GLP-1 response in obese subjects, which was significantly increased after a 6-month $15 \%$ diet-induced weight loss and appeared to be intermediate between the GLP-1 responses for obese and lean subjects, pointing toward a gradual normalization of GLP-1 responses with weight loss (7). However, other weight loss intervention studies have reported decreased $(13,14$, $15)$ and unaltered (16) postprandial GLP-1 levels after a diet-induced weight loss.

PYY $_{3-36}$ is another gut-derived satiety hormone, and postprandial levels are attenuated in obesity (17), perhaps in agreement with the finding that it is secreted together with GLP-1 from the intestinal L cells (18). The effect of weight loss on $\mathrm{PYY}_{3-36}$ levels is, however, less clear, and both decreased (15) and unchanged (19) levels have been reported. Both fasting (20) and postprandial levels (21) increase after gastric bypass, and again, the effect seems to be larger after RYGB than after gastric banding.

The incretin hormone, glucose-dependent insulinotropic polypeptide (GIP), is secreted from the upper small intestine (22). In mice, GIP has been shown to promote energy storage via direct actions on adipose tissue by enhancing the activity of lipoprotein lipase (LPL) and to promote insulin-dependent free fatty acid uptake in adipocytes (23). Furthermore, a study has shown that GIP receptor knockout mice have reduced subcutaneous adipose tissue, improved insulin sensitivity, and were resistant to diet-induced obesity (24). However, a recent study examining 1405 individuals at low to high risk of developing type 2 diabetes found that high fasting GIP levels were associated with lower LDL levels, independent of insulin, indicating that high GIP levels may promote lipid clearance from the blood (25). GIP probably does not possess any appetiteregulating properties, but levels have been suggested to be exaggerated in obesity and diabetes (26). The effect of weight loss on GIP levels is not well established in obesity, and both lower (7) and higher postprandial levels (27) have been reported.

The orexigenic hormone, ghrelin, is primarily secreted from the stomach and duodenum (28), and responds rapidly to a negative energy balance. Thus, after dietinduced weight loss, fasting ghrelin concentrations and, in parallel, feelings of hunger, increase (29). Therefore, ghrelin has been suggested to be involved in both shortterm (meal initiation and termination) and long-term regulation of appetite and body weight (30).

Finally, the pancreatic hormones, glucagon and insulin, have also been suggested to be involved in satiety (31). Early studies have shown that administration of glucagon may reduce appetite in humans (32), but the physiological relevance of these findings has not been confirmed. However, combined administration of low doses of GLP-1 and glucagon inhibited food intake significantly and induced c-fos expression in the area postrema and amygdala in mice (33), and co-infusion of GLP-1 and glucagon has been shown to reduce food intake in humans (34).

Thus, the responses of appetite-regulating hormones after diet-induced weight loss remain unclear, and most studies have only assessed short-term effects of weight reduction. Therefore, the aim of this study was to assess meal-induced responses of the gastrointestinal hormones: GLP-1, GIP, PYY ${ }_{3-36}$, ghrelin as well as the pancreatic hormones glucagon and insulin, both acutely and after 1 year of diet-induced weight loss maintenance in order to identify hormonal changes associated with maintained weight loss.

\section{Subjects and methods}

Twenty obese non-type 2 diabetic individuals (BMI: $30.0-39.9 \mathrm{~kg} / \mathrm{m}^{2}$ ) aged $18-65$ years were recruited for the study. Participants suffering from acute or chronic illnesses (including diabetes) or participants taking any form of medical treatment with known effects on glucose and lipid metabolism were excluded before entering the study. See previously published article (35) for a detailed study description.

\section{Weight loss phase}

The study participants were instructed by a clinical dietician on how to adhere to a low-calorie powder diet 
of $810 \mathrm{kcal} /$ day for 8 weeks. Products were provided by the Cambridge Diet (Cambridge Weight Plan, Corby, UK) (36). The low-calorie diet program consisted of a powdered formula mixture dissolved in skimmed milk or water. The program met all recommendations for daily intake of essential amino acids, fatty acids, vitamins, and minerals. During the weight loss phase, the participants had weekly consultations with the dietician who assisted them in achieving a body weight loss above $7.5 \%$, which was required in order to continue into the 52-week weight loss maintenance program.

\section{Weight loss maintenance phase}

After 8 weeks on the low-calorie diet, the study participants followed Cambridge Weight Loss Maintenance Program with Cambridge Weight Plan products. Study participants were instructed to restrict calorie intake after calculation of their estimated daily energy need (from the Schofield equation (37) multiplied with the individual physical activity level score) and subsequently subtracted by $600 \mathrm{kcal}$ (mean daily energy requirement subtracted by $600 \mathrm{kcal}$ was $1395 \pm 31 \mathrm{kcal}$, 95\% CI (1267 - 1893). During the 52 weeks, the participants attended 13 consultations with the clinical dietician in which they received education on diet and lifestyle changes and were encouraged to follow the 'Nordic Nutrition Recommendations' (38). The participants kept track on their energy intake by recording this in a diet calendar which they brought to the consultations. In case of weight gain, up to two meals a day during the weight loss maintenance period were allowed to be replaced by Cambridge Weight Plan products to ensure a stable maintenance of weight loss.

\section{Meal test}

The study participants completed a 3-h meal test before weight loss, after weight loss, and after 52 weeks of weight loss maintenance. After an overnight fast $(10-12 \mathrm{~h})$, participants were placed resting in a recumbent position, and a cannula was inserted into a cubital vein for blood sampling. After fasting blood samples were drawn, the participants ingested an energy-dense nutrient drink (Fresubin; Fresenius Kabi Deutschland $\mathrm{GmbH}$, Bad Homburg, Germany) of 600 kilo calories (20\% protein, $30 \%$ fat, and $50 \%$ carbohydrate). The meal was consumed over a period of $15 \mathrm{~min}$. For each meal test, venous blood samples were drawn 10,5 , and 0 min before (fasting state) and $15,30,45,60,90,120$, and 180 min after meal intake.

\section{Outcome measures}

Plasma $\mathrm{PYY}_{3-36}$ and total plasma ghrelin were measured by radioimmunoassay (Millipore). All quality controls were within the prespecified limits. Radioimmunological determinations of total plasma GLP-1, total plasma GIP (total=sum of the active hormone and the primary metabolites, GLP-1 (9-36 amide), and GIP (3-42), respectively), and plasma glucagon were performed as described $(39,40,41)$. The assays have a detection limit of less than $2 \mathrm{pmol} / \mathrm{L}$ and an intra-assay and inter-assay coefficients of variation of less than 6 and 15\% respectively. Plasma glucose was measured with the glucose oxidase technique (YSI 2300 STAT Plus; Yellow Springs Instrument, Yellow Springs, OH, USA). Serum insulin concentrations were measured using Immulite 2000 solid-phase chemiluminescent immunometric assays (Immulite 2000; Siemens). Body composition (fat and lean body mass) was assessed using dual-energy X-ray absorptiometry scanning (Hologic discovery A, Bedford, MA, USA).

\section{Ethical issues}

The study was approved by the ethical committee in Copenhagen (reference number: H-4-2010-134) and was performed in accordance with the Helsinki Declaration II and with The International Council for Harmonisation of Good Clinical Practice (ICH-GCP). Participation in the investigation was voluntary, and the individuals could at any time retract their consent to participate (ClinicalTrials. gov Identifier: NCT02094183).

\section{Statistical analysis}

Within-subject variances from before to after weight loss and from before weight loss to week 52 were analyzed with paired $t$-tests, and linear regression analyses were made with log-transformed values (SPSS statistics version 22; IBM). Total and incremental areas under the curve (AUC) were calculated using Prism Version 5.04 (GraphPad) by the trapezoidal method, which is a validated tool for postprandial assessments (42). Incremental AUC (iAUC) was defined as the area above the baseline (defined by mean hormone levels at $t=-15,-5$, and 0 min before meal ingestion), thus covering time points $0-180 \mathrm{~min}$. 
Incremental AUC was used when there were no differences in fasting (from baseline to week 52) whereas total AUC was used when there were differences in fasting levels in order to account for relevant hormone response.

Homeostasis model assessment (HOMA) for insulin sensitivity was calculated as follows (43):

HOMA $-\mathrm{IR}=\frac{(\text { fasting glucose }(\mathrm{mmol} / \mathrm{L}) \times \text { fasting insulin }(\mu \mathrm{IU} / \mathrm{mL}))}{22.5}$

The Matsuda index of insulin sensitivity was calculated as follows (44):

Matsuda index
$=\frac{10.000}{\sqrt{(\text { fasting insulin } \times \text { fasting glucose } \times 2 \text {-h insulin } \times 2 \text {-h glucose })}}$

The Matsuda index was calculated with insulin in $\mu \mathrm{U} / \mathrm{mL}$ and glucose in $\mathrm{mg} / \mathrm{dL}$. Data were obtained from meal tests as described previously rather than from an oral glucose tolerance test. Data are shown as mean \pm S.E.M. A two-tailed $P$-value less than 0.05 was considered significant.

Data were tested for normal distribution with the Shapiro-Wilk test.

\section{Results}

\section{Weight change and body mass composition}

After the very-low calorie diet, the study participants achieved a total weight loss of $12.5 \mathrm{~kg}$ equivalent to $13 \%$ of initial body weight, $P<0.0001$. After 1 year, the study participants had maintained their weight loss, with no significant weight difference from after initial weight loss to week 52 (weight difference: $2.2 \mathrm{~kg}$ (95\% CI: -1.2 to 5.6$), P=0.2)$. Fat mass decreased by $6.3 \%$ from before to after weight loss $(P<0.0001)$, and by week 52 , the total fat mass decrease was $8.3 \%(P=0.002)$ compared with before weight loss. Lean body mass (calculated without bone mass) increased by $3.8 \%$ from before to after weight loss $(P<0.0001)$, and after 52 weeks of weight loss maintenance, the lean body mass increased additionally by $1.4 \%$ to a total of $5.2 \%(P<0.0001)$ from before weight loss (Table 1).

\section{Hormonal changes}

The incremental area under the GLP-1 response curve increased by $44 \%(P=0.04)$ from before to after weight loss and increased by additional $28 \%$ at week 52 , that is, a total increase of $72 \%$ compared with before weight loss $(P=0.0001)$. Fasting GLP-1 levels remained unchanged (Fig. 1A).

Incremental area under the GIP response curve increased by $36 \%(P=0.001)$ from before to after weight loss, but at week 52, GIP levels had returned to beforeweight loss values $(P=0.9)$. Fasting GIP levels remained unchanged (Fig. 1B).

The incremental area under the $\mathrm{PYY}_{3-36}$ response curve increased by $74 \%(P<0.0001)$ from before to after weight loss, and by week 52, the incremental area under the curve was increased by $36 \%$ from before-weight loss values $(P=0.02)$. Fasting plasma levels of $P Y Y_{3-36}$ decreased by $13 \%$ from before to after weight loss $(P=0.03)$ but reverted to before-weight loss values at week $52(P>0.05)$ (Fig. 1C).

Total area under the ghrelin response curve increased by $23 \%$ from before to after weight loss $(P<0.0001)$, but by week 52 , the total increase from before weight loss was reduced by $7 \%$ to a total of $16 \%(P=0.005)$. Fasting ghrelin levels increased by $25 \%$ from before to after weight loss $(P<0.0001)$, but at week 52 , the increase was reduced to $17 \%$ from before weight loss $(P=0.01)$ (Fig. 1D). Mealstimulated as well as fasting glucagon levels remained unchanged throughout the study period (Fig. 1E).

Total area under the insulin response curve decreased by $19 \%$ from before to after weight loss $(P=0.02)$ and remained significantly lower throughout the weight loss maintenance period (17\% lower than before weight loss, $P=0.04$ ). Fasting insulin levels decreased by almost $40 \%$ immediately after weight loss $(P<0.0001)$ and remained low throughout the weight loss maintenance phase, although tended to revert toward before-weight loss values (17\% lower than before weight loss, $P=0.002$ ) (Fig. 1F).

HOMA-IR decreased significantly from before weight loss to after weight loss (estimated difference: -0.96 (95\% CI: $0.5-1.4), P<0.0001)$ and remained lower than before weight loss after 52 weeks (estimated difference: -0.4 (95\% CI: $0.1-0.7), P=0.01$ ) (Table 2).

The Matsuda index of insulin sensitivity improved after weight loss (estimated difference: 0.5 (95\% CI: $0.1-0.9), P=0.016$ and tended to remain elevated at week 52 , although not significantly (estimated difference: 0.4 (95\% CI: 0.04-0.8), $P=0.08$ ) (Table 2).

\section{Discussion}

In this study, we were able to demonstrate that after 1 year of successful 13\% body weight loss maintenance, the meal responses of the appetite-inhibiting hormones 
苗

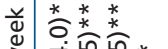

$* *$ 年

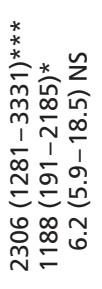

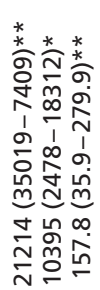

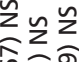

응종엉

운은응

in 10

ㅇํ के

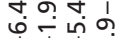

$\frac{1}{1} \frac{1}{1}=$

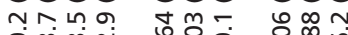

1)

@i

$\perp=1$

$\overline{\dot{r}} \bar{N} \hat{m}$
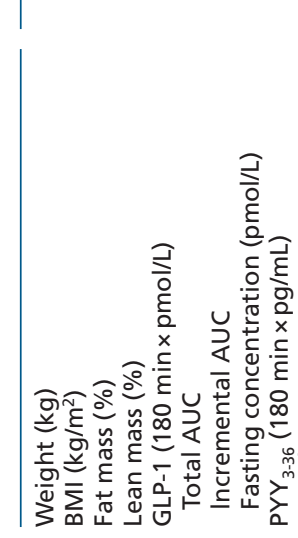
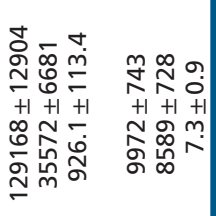

GLP-1 and PYY ${ }_{3-36}$ remain significantly increased, whereas the orexigenic hormone ghrelin and the lipid-regulating hormone GIP after an initial increase revert toward beforeweight loss values. Glucagon levels were not affected by weight loss.

In 1997, Näslund et al. described elevated levels of both fasting and postprandial GLP-1, PYY $3-36$, and cholecystokinin (CCK) 20 years after jejunoileal bypass surgery. However, it was unsettled whether this increase was associated with the weight loss or the operation, which in itself induced a change in gut hormone secretion due to increased exposure of the terminal ileum to food components (45). Today, it is well recognized that postprandial GLP-1 and $\mathrm{PYY}_{3-36}$ secretion is increased in obese patients after bypass surgery (20). Thus, in patients receiving RYGB surgery, the increase in GLP-1 and PYY ${ }_{3-36}$ is evident before significant weight loss and is thought to be due to the altered transit of nutrients through the gut (46). However, it is of notice that in studies of good and poor RYGB responders (with larger and smaller weight losses, respectively), $\mathrm{PYY}_{3-36}$ and GLP-1 responses were associated with the magnitude of the weight loss $(47,48)$. Additionally, it was shown that suppression of GLP-1 and PYY $_{3-36}$ with somatostatin was associated with the return of appetite and food intake (48), and it was suggested that poor weight loss maintenance might be associated with attenuated postprandial responses of $\mathrm{PYY}_{3-36}$ and GLP-1 compared with patients with sustained weight losses (47, 48). Thus, these studies might suggest that the ability of the patients to secrete the appetite inhibitory hormones would predict the resulting weight loss.

Based on the current results, we propose that the ability to maintain weight loss depends on the restoration of the secretion of the appetite-regulating hormones. Furthermore, weight gain may be associated with a gradual impairment in the secretion of these hormones, initiating a vicious cycle with progressively deteriorating appetite regulation. The changes we observe do not seem compatible with decreased secretion of the appetiteregulating hormones as a primary cause of obesity, because a primary deficiency would not be expected to disappear after weight loss. Thus, the increase in GLP-1 and $\mathrm{PYY}_{3-36}$ responses after long-term weight loss supports the concept of decreased hormone responses in obesity and therefore secondary to the obese state. Accordingly, lifting of obesity (and especially reducing fat mass) ameliorates impairment of secretion and facilitates maintenance of a weight loss.

We observe a significant improvement in both HOMA-IR and the Matsuda index of insulin sensitivity 

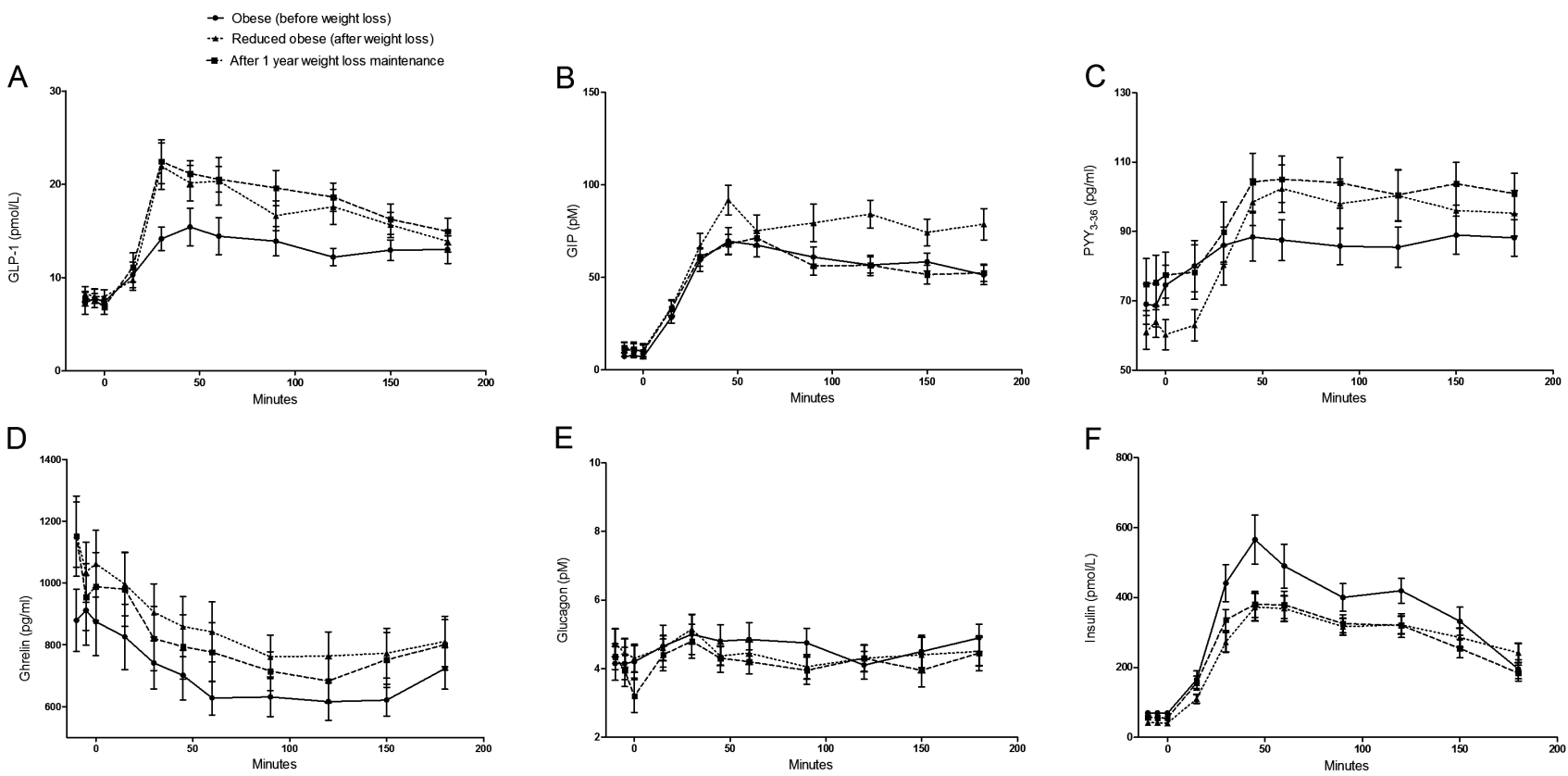

\section{Figure 1}

Plasma hormone responses to a meal test before weight loss (circle full line), after weight loss (triangle dotted line), and after 1 year of weight loss maintenance (square stippled line). (A) Area under the GLP-1 response curve. (B) Area under the GIP response curve. (C) Area under the $\mathrm{PYY}_{3-36}$ response. (D) Area under the ghrelin response curve. (E) Area under the glucagon response curve. (F) Area under the insulin response. Liquid meals were ingested at timepoint 0.

immediately after weight loss, and HOMA-IR remained low after 1 year of weight loss maintenance. This supports the hypothesis that the GLP-1-secreting L cells exhibit insulin sensitivity and thus develop some degree of insulin resistance in the obese state (49). Accordingly, the observed improvement in insulin sensitivity after acute and maintained fat mass loss could explain the sustained increase in GLP-1 release, supporting the notion of an inverse correlation between GLP-1 and insulin (7). PYY ${ }_{3-36}$ secretion showed similar increases along with changes in fasting basal secretion, making the pattern less clear. However, it is now known that not all L cells secrete both PYY 3-36 $_{\text {and GLP-1 - }}$ many particularly proximal L cells secrete only GLP-1 and this may explain the discrepant findings of weight loss effects on fasting PYY $\mathrm{PY}_{36}$ and GLP-1 levels (50)

It is well known that obese individuals display lower levels of the hunger hormone ghrelin (51) and that concentrations rapidly increase during dietary restriction and exercise $(29,52)$. Furthermore, it has been suggested that ghrelin plays a role in long-term weight maintenance (30). Our results demonstrate that ghrelin levels respond rapidly to acute energy restriction, but gradually return to before-weight loss values after 1 year of weight loss maintenance, indicating that ghrelin is a short-term regulator of appetite. Furthermore, that the acute ghrelin-mediated appetite stimulation that occurs during acute weight loss is transient and that long-term adaptation to a new weight level does not necessarily involve increased ghrelin-mediated appetite stimulation.

The early increased ghrelin levels might be viewed as a compensatory mechanism to preserve body weight even if excessive. However, after long-term weight loss maintenance, ghrelin concentrations have almost returned to before-weight loss levels, which may be viewed as an adaptation response and actually helps to facilitate maintenance of the new body weight especially combined with the sustained increase in the appetite hormones GLP-1 and PYY ${ }_{3-36}$.

We report a temporary increase in the intestinal hormone GIP in acute response to weight loss. Our results are in contrast to those of Verdich et al., who reported an impaired postprandial GIP response after weight loss (7), leading to a hypothesis of exaggerated levels in obesity, which become normalized when excess body weight is lost (26). Our findings are in agreement with the observations by Raben et al., who reported an increase in postprandial GIP levels in 
post-obese women compared with obese controls (27). The obesogenic effect of postprandial GIP is well described and is probably attributed to the anabolic effect of the hormone on adipose tissue rather than a centrally mediated effect on appetite regulation (53). Although not verified, it could be speculated that, as for ghrelin, the acute increases in postprandial GIP following weight loss are part of the body's acute compensatory mechanisms to avoid depletion of energy stores, and increasing postprandial GIP levels represent an attempt to facilitate fat storage. However, as for ghrelin, the response is only temporary - when weight loss is sustained, postprandial GIP returns to before-weight loss levels, thereby, with time, facilitating weight maintenance.

Glucagon levels did not change throughout the study period, and besides a few early studies (32, 54), no documentation for a direct appetite-regulating effect in humans has been demonstrated. Thus, we conclude that glucagon does not seem to be involved in weight loss mechanisms in humans, although it may act synergistically in combination with GLP-1 (34).

Finally, a surprising finding in the study was an increase in lean body mass during the weight loss program. However, the composition of the diet (more protein) combined with a possibly increased level of exercise may have led to an increase in muscle mass and therefore lean body mass.

\section{Strengths and limitations}

We were able to introduce and maintain a large fat mass loss over 1 year, which made it possible to analyze any accompanying changes in hormonal response during maintained fat loss uninfluenced by fat regain. We performed meal tests in this study, which is the golden standard for evaluating GLP-1, PYY ${ }_{3-36}$, ghrelin, and GIP responses, and also provides information about glucagon secretion. We used well-documented assay methods with high specificity and sensitivity for analyzing the plasma samples $(39,40,41)$. Many studies of hormone secretion have been carried out with various commercially available kits, although the specificity and sensitivity of these kits for hormonal analysis may vary considerably (55). For instance, measurements of peripheral circulating levels of the intact GLP-1 molecular form, GLP-1-(7-36) $\mathrm{NH}_{2} /$ GLP-1-(7-37), only reflect the small fraction of the hormone that reaches its targets via the classical endocrine route after having exerted the predominant part of its actions via the 
nervous system (56); such assays therefore are not suitable for measurements of GLP-1 secretion, which requires determination of the sum of the intact form and its primary, N-terminally truncated metabolites. Finally, we have measured total ghrelin that comprises both the acylated and the deacylated forms and thus represents total ghrelin secretion $(57,58)$.

\section{Conclusions}

Collectively, we show that after 1 year of weight loss maintenance, meal responses of the appetite-inhibiting hormones GLP-1 and $\mathrm{PYY}_{3-36}$ remain significantly increased, whereas levels of the orexigenic hormone ghrelin and the lipid-regulatory hormone GIP tend to revert toward before-weight loss values, indicating that an increase in appetite-inhibiting mechanisms and a partly decrease in appetite-stimulating mechanisms appear to contribute to successful long-term weight loss maintenance.

\section{Declaration of interest}

The authors declare that there is no conflict of interest that could be perceived as prejudicing the impartiality of the research reported.

\section{Funding}

The project was supported by funding from the Danish Diabetes Academy supported by the Novo Nordisk Foundation, the Danish Research Council for Health and Disease (reference number: 11-107683) and the University Investment Capital (UNIK): Food, Fitness \& Pharma for Health and Disease from the Danish Ministry of Science, Technology and Innovation. Cambridge Weight Plan products were donated from Cambridge Weight Plan. The funding sponsors were not involved in study design, conduct of the study, data analysis, or approval of the manuscript.

\section{Author contribution statement}

S S T, J J H, and S M designed the study. E W I and $\mathrm{J} L$ conducted the study and collected data. E W I wrote the manuscript and analyzed data. J J H, S M, S S T and L H contributed to discussion, reviewed/edited the manuscript and approved the final version.

\section{Acknowledgments}

We thank the study participants, the dieticians Jane Hjort and Stine Rasmussen, Hvidovre Hospital, Hvidovre, Denmark, and lab technician Lene Albæk, University of Copenhagen, København, Denmark.

\section{References}

1 Wing RR \& Hill JO. Successful weight loss maintenance. Annual Review of Nutrition 200121 323-341. (doi:10.1146/annurev. nutr.21.1.323)
2 Wadden TA. Treatment of obesity by moderate and severe caloric restriction. Results of clinical research trials. Annals of Internal Medicine 1993119 688-693. (doi:10.7326/0003-4819-119-7_Part_2199310011-00012)

3 Flint A, Raben A, Astrup A \& Holst JJ. Glucagon-like peptide 1 promotes satiety and suppresses energy intake in humans. Journal of Clinical Investigation 1998101 515-520. (doi:10.1172/JCI990)

4 Chelikani PK, Haver AC \& Reidelberger RD. Intravenous infusion of glucagon-like peptide-1 potently inhibits food intake, sham feeding, and gastric emptying in rats. American Journal of Physiology. Regulatory, Integrative and Comparative Physiology 2005288 R1695-R1706. (doi:10.1152/ajpregu.00870.2004)

5 Tang-Christensen M, Larsen PJ, Goke R, Fink-Jensen A, Jessop DS, Moller M \& Sheikh SP. Central administration of GLP-1-(7-36) amide inhibits food and water intake in rats. American Journal of Physiology 1996271 R848-R856.

6 Muscelli E, Mari A, Casolaro A, Camastra S, Seghieri G, Gastaldelli A, Holst JJ \& Ferrannini E. Separate impact of obesity and glucose tolerance on the incretin effect in normal subjects and type 2 diabetic patients. Diabetes 200857 1340-1348. (doi:10.2337/db07-1315)

7 Verdich C, Toubro S, Buemann B, Lysgard Madsen J, Juul Holst J \& Astrup A. The role of postprandial releases of insulin and incretin hormones in meal-induced satiety - effect of obesity and weight reduction. International Journal of Obesity and Related Metabolic Disorders 200125 1206-1214.

8 Carr RD, Larsen MO, Jelic K, Lindgren O, Vikman J, Holst JJ, Deacon CF \& Ahren B. Secretion and dipeptidyl peptidase-4-mediated metabolism of incretin hormones after a mixed meal or glucose ingestion in obese compared to lean, nondiabetic men. Journal of Clinical Endocrinology and Metabolism 201095 872-878. (doi:10.1210/ jc.2009-2054)

9 Faerch K, Torekov SS, Vistisen D, Johansen NB, Witte DR, Jonsson A, Pedersen O, Hansen T, Lauritzen T, Sandbaek A et al. Glucagon-like peptide-1 (GLP-1) response to oral glucose is reduced in pre-diabetes, screen-detected type 2 diabetes and obesity, and influenced by sex: the ADDITION-PRO study. Diabetes 201564 2513-2525. (doi:10.2337/db14-1751)

10 Jorgensen NB, Dirksen C, Bojsen-Moller KN, Jacobsen SH, Worm D, Hansen DL, Kristiansen VB, Naver L, Madsbad S \& Holst JJ. Exaggerated glucagon-like peptide 1 response is important for improved beta-cell function and glucose tolerance after Roux-en-Y gastric bypass in patients with type 2 diabetes. Diabetes 201362 3044-3052. (doi:10.2337/db13-0022)

11 Naslund E, Gryback P, Backman L, Jacobsson H, Holst JJ, Theodorsson E \& Hellstrom PM. Distal small bowel hormones: correlation with fasting antroduodenal motility and gastric emptying. Digestive Diseases and Sciences 199843 945-952. (doi:10.102 3/A:1018806129102)

12 Korner J, Bessler M, Inabnet W, Taveras C \& Holst JJ. Exaggerated glucagon-like peptide-1 and blunted glucose-dependent insulinotropic peptide secretion are associated with Roux-en-Y gastric bypass but not adjustable gastric banding. Surgery for Obesity and Related Diseases 20073 597-601. (doi:10.1016/j. soard.2007.08.004)

13 Adam TC, Lejeune MP \& Westerterp-Plantenga MS. Nutrientstimulated glucagon-like peptide 1 release after body-weight loss and weight maintenance in human subjects. British Journal of Nutrition 200695 160-167. (doi:10.1079/BJN20051614)

14 de Luis DA, Gonzalez Sagrado M, Conde R, Aller R \& Izaola O. Decreased basal levels of glucagon-like peptide-1 after weight loss in obese subjects. Annals of Nutrition and Metabolism 200751 134-138. (doi:10.1159/000103273)

15 Sumithran P, Prendergast LA, Delbridge E, Purcell K, Shulkes A Kriketos A \& Proietto J. Long-term persistence of hormonal adaptations to weight loss. New England Journal of Medicine 2011365 1597-1604. (doi:10.1056/NEJMoa1105816) 
16 Svendsen PF, Jensen FK, Holst JJ, Haugaard SB, Nilas L \& Madsbad S. The effect of a very low calorie diet on insulin sensitivity, beta cell function, insulin clearance, incretin hormone secretion, androgen levels and body composition in obese young women. Scandinavian Journal of Clinical and Laboratory Investigation 201272 410-419. (doi:10.3109/00365513.2012.691542)

17 le Roux CW, Batterham RL, Aylwin SJ, Patterson M, Borg CM, Wynne KJ, Kent A, Vincent RP, Gardiner J, Ghatei MA et al. Attenuated peptide YY release in obese subjects is associated with reduced satiety. Endocrinology 2006147 3-8. (doi:10.1210/ en.2005-0972)

18 Habib AM, Richards P, Rogers GJ, Reimann F \& Gribble FM. Co-localisation and secretion of glucagon-like peptide 1 and peptide YY from primary cultured human L cells. Diabetologia 201356 1413-1416. (doi:10.1007/s00125-013-2887-z)

19 Scheid JL, De Souza MJ, Leidy HJ \& Williams NI. Ghrelin but not peptide YY is related to change in body weight and energy availability. Medicine \& Science in Sports \& Exercise 201143 2063-2071. (doi:10.1249/MSS.0b013e31821e52ab)

20 Jacobsen SH, Olesen SC, Dirksen C, Jorgensen NB, BojsenMoller KN, Kielgast U, Worm D, Almdal T, Naver LS, Hvolris LE et al. Changes in gastrointestinal hormone responses, insulin sensitivity, and beta-cell function within 2 weeks after gastric bypass in non-diabetic subjects. Obesity Surgery 201222 1084-1096. (doi:10.1007/s11695-012-0621-4)

21 Korner J, Inabnet W, Febres G, Conwell IM, McMahon DJ, Salas R, Taveras C, Schrope B \& Bessler M. Prospective study of gut hormone and metabolic changes after adjustable gastric banding and Rouxen-Y gastric bypass. International Journal of Obesity 200933 786-795. (doi:10.1038/ijo.2009.79)

22 Meier JJ, Nauck MA, Schmidt WE \& Gallwitz B. Gastric inhibitory polypeptide: the neglected incretin revisited. Regulatory Peptides 2002 107 1-13. (doi:10.1016/S0167-0115(02)00039-3)

$23 \mathrm{Kim}$ SJ, Nian C \& McIntosh CH. Resistin is a key mediator of glucose-dependent insulinotropic polypeptide (GIP) stimulation of lipoprotein lipase (LPL) activity in adipocytes. Journal of Biological Chemistry 2007282 34139-34147. (doi:10.1074/jbc. M704896200)

24 Miyawaki K, Yamada Y, Ban N, Ihara Y, Tsukiyama K, Zhou H, Fujimoto S, Oku A, Tsuda K, Toyokuni S et al. Inhibition of gastric inhibitory polypeptide signaling prevents obesity. Nature Medicine 20028 738-742. (doi:10.1038/nm727)

25 Moller CL, Vistisen D, Faerch K, Johansen NB, Witte DR, Jonsson A, Pedersen $\mathrm{O}$, Hansen $\mathrm{T}$, Lauritzen $\mathrm{T}$, Jorgensen ME et al. Glucosedependent insulinotropic polypeptide (GIP) is associated with lower LDL but unhealthy fat distribution, independent of insulin: the ADDITION-PRO study. Journal of Clinical Endocrinology and Metabolism 2015101 485-493. (doi:10.1210/jc.2015-3133).

26 Vilsboll T, Krarup T, Sonne J, Madsbad S, Volund A, Juul AG \& Holst JJ. Incretin secretion in relation to meal size and body weight in healthy subjects and people with type 1 and type 2 diabetes mellitus. Journal of Clinical Endocrinology and Metabolism 200388 2706-2713. (doi:10.1210/jc.2002-021873)

27 Raben A, Andersen HB, Christensen NJ, Madsen J, Holst JJ \& Astrup A. Evidence for an abnormal postprandial response to a high-fat meal in women predisposed to obesity. American Journal of Physiology 1994 267 E549-E559.

28 Date Y, Kojima M, Hosoda H, Sawaguchi A, Mondal MS, Suganuma T, Matsukura S, Kangawa K \& Nakazato M. Ghrelin, a novel growth hormone-releasing acylated peptide, is synthesized in a distinct endocrine cell type in the gastrointestinal tracts of rats and humans. Endocrinology 2000141 4255-4261.

29 Kotidis EV, Koliakos GG, Baltzopoulos VG, Ioannidis KN, Yovos JG \& Papavramidis ST. Serum ghrelin, leptin and adiponectin levels before and after weight loss: comparison of three methods of treatment - a prospective study. Obesity Surgery 200616 1425-1432.
30 Cummings DE. Ghrelin and the short- and long-term regulation of appetite and body weight. Physiology \& Behavior 200689 71-84. (doi:10.1016/j.physbeh.2006.05.022)

31 Filippi BM, Abraham MA, Yue JT \& Lam TK. Insulin and glucagon signaling in the central nervous system. Reviews in Endocrine and Metabolic Disorders 201314 365-375. (doi:10.1007/s11154-013-9258-4)

32 Geary N, Kissileff HR, Pi-Sunyer FX \& Hinton V. Individual but not simultaneous, glucagon and cholecystokinin infusions inhibit feeding in men. American Journal of Physiology 1992262 R975-R980.

33 Parker JA, McCullough KA, Field BC, Minnion JS, Martin NM, Ghatei MA \& Bloom SR. Glucagon and GLP-1 inhibit food intake and increase c-fos expression in similar appetite regulating centres in the brainstem and amygdala. International Journal of Obesity 201337 1391-1398. (doi:10.1038/ijo.2012.227)

34 Cegla J, Troke RC, Jones B, Tharakan G, Kenkre J, McCullough KA, Lim CT, Parvizi N, Hussein M, Chambers ES et al. Coinfusion of low-dose GLP-1 and glucagon in man results in a reduction in food intake. Diabetes 201463 3711-3720. (doi:10.2337/db14-0242)

35 Iepsen EW, Lundgren J, Dirksen C, Jensen JE, Pedersen O, Hansen T, Madsbad S, Holst JJ \& Torekov SS. Treatment with a GLP-1 receptor agonist diminishes the decrease in free plasma leptin during maintenance of weight loss. International Journal of Obesity 201439 834-841. (doi:10.1038/ijo.2014.177)

36 Riecke BF, Christensen R, Christensen P, Leeds AR, Boesen M, Lohmander LS, Astrup A \& Bliddal H. Comparing two low-energy diets for the treatment of knee osteoarthritis symptoms in obese patients: a pragmatic randomized clinical trial. Osteoarthritis Cartilage 201018 746-754. (doi:10.1016/j.joca.2010.02.012)

37 Schofield WN. Predicting basal metabolic rate, new standards and review of previous work. Human Nutrition. Clinical Nutrition 198539 (Supplement 1) 5-41.

38 Ministers NCo. Nordic Nutrition Recommendations 2012. Nordic Council of Ministers.

39 Orskov C, Rabenhoj L, Wettergren A, Kofod H \& Holst JJ. Tissue and plasma concentrations of amidated and glycine-extended glucagonlike peptide I in humans. Diabetes 199443 535-539. (doi:10.2337/ diab.43.4.535)

40 Deacon CF, Nauck MA, Meier J, Hucking K \& Holst JJ. Degradation of endogenous and exogenous gastric inhibitory polypeptide in healthy and in type 2 diabetic subjects as revealed using a new assay for the intact peptide. Journal of Clinical Endocrinology and Metabolism 2000 85 3575-3581.

41 Orskov C, Jeppesen J, Madsbad S \& Holst JJ. Proglucagon products in plasma of noninsulin-dependent diabetics and nondiabetic controls in the fasting state and after oral glucose and intravenous arginine. Journal of Clinical Investigation 199187 415-423. (doi:10.1172/JCI115012)

42 Le Floch JP, Escuyer P, Baudin E, Baudon D \& Perlemuter L. Blood glucose area under the curve. Methodological aspects. Diabetes Care 199013 172-175. (doi:10.2337/diacare.13.2.172)

43 Wallace TM, Levy JC \& Matthews DR. Use and abuse of HOMA modeling. Diabetes Care 200427 1487-1495. (doi:10.2337/ diacare.27.6.1487)

44 Matsuda M \& DeFronzo RA. Insulin sensitivity indices obtained from oral glucose tolerance testing: comparison with the euglycemic insulin clamp. Diabetes Care 199922 1462-1470. (doi:10.2337/diacare.22.9.1462)

45 Naslund E, Gryback P, Hellstrom PM, Jacobsson H, Holst JJ, Theodorsson E \& Backman L. Gastrointestinal hormones and gastric emptying 20 years after jejunoileal bypass for massive obesity. International Journal of Obesity and Related Metabolic Disorders 199721 387-392. (doi:10.1038/sj.ijo.0800418)

46 Dirksen C, Jorgensen NB, Bojsen-Moller KN, Jacobsen SH, Hansen DL, Worm D, Holst JJ \& Madsbad S. Mechanisms of improved glycaemic control after Roux-en-Y gastric bypass. Diabetologia 201255 1890-1901. (doi:10.1007/s00125-012-2556-7)

47 Dirksen C, Jorgensen NB, Bojsen-Moller KN, Kielgast U, Jacobsen SH, Clausen TR, Worm D, Hartmann B, Rehfeld JF, 
Damgaard $\mathrm{M}$ et al. Gut hormones, early dumping and resting energy expenditure in patients with good and poor weight loss response after Roux-en-Y gastric bypass. International Journal of Obesity 201337 1452-1459. (doi:10.1038/ijo.2013.15)

48 le Roux CW, Welbourn R, Werling M, Osborne A, Kokkinos A, Laurenius A, Lonroth H, Fandriks L, Ghatei MA, Bloom SR et al. Gut hormones as mediators of appetite and weight loss after Roux-en-Y gastric bypass. Annals of Surgery 2007246 780-785. (doi:10.1097/ SLA.0b013e3180caa3e3)

49 Rask E, Olsson T, Soderberg S, Holst Jj, Tura A, Pacini G \& Ahren B. Insulin secretion and incretin hormones after oral glucose in nonobese subjects with impaired glucose tolerance. Metabolism $2004 \mathbf{5 3}$ 624-631. (doi:10.1016/j.metabol.2003.11.011)

50 Svendsen B, Pedersen J, Jacob Wewer Albrechtsen N, Hartmann B, Torang S, Rehfeld JF, Seier Poulsen S \& Holst JJ. An analysis of co-secretion and co-expression of gut hormones from male rat proximal and distal small intestine. Endocrinology 2014156 847-857. (doi:10.1210/en.2014-1710).

51 Soriano-Guillen L, Barrios V, Campos-Barros A \& Argente J. Ghrelin levels in obesity and anorexia nervosa: effect of weight reduction or recuperation. Journal of Pediatrics 2004144 36-42. (doi:10.1016/ j.jpeds.2003.10.036)

52 Purnell JQ, Cummings D \& Weigle DS. Changes in 24-h area-underthe-curve ghrelin values following diet-induced weight loss are associated with loss of fat-free mass, but not with changes in fat mass, insulin levels or insulin sensitivity. International Journal of Obesity 200731 385-389. (doi:10.1038/sj.ijo.0803401)
53 Asmar M, Tangaa W, Madsbad S, Hare K, Astrup A, Flint A, Bulow J \& Holst JJ. On the role of glucose-dependent insulintropic polypeptide in postprandial metabolism in humans. American Journal of Physiology - Endocrinology and Metabolism 2010298 E614-E621. (doi:10.1152/ajpendo.00639.2009)

54 Le Sauter J, Noh U \& Geary N. Hepatic portal infusion of glucagon antibodies increases spontaneous meal size in rats. American Journal of Physiology 1991261 R162-R165.

55 Bak MJ, Wewer Albrechtsen NJ, Pedersen J, Knop FK, Vilsboll T, Jorgensen NB, Hartmann B, Deacon CF, Dragsted LO \& Holst JJ. Specificity and sensitivity of commercially available assays for glucagon-like peptide-1 (GLP-1): implications for GLP-1 measurements in clinical studies. Diabetes, Obesity and Metabolism 201416 1155-1164. (doi:10.1111/dom.2014.16.issue-11)

56 Kuhre RE, Wewer Albrechtsen NJ, Hartmann B, Deacon CF \& Holst JJ. Measurement of the incretin hormones: glucagon-like peptide- 1 and glucose-dependent insulinotropic peptide. Journal of Diabetes and Its Complications 201529 445-450. (doi:10.1016/j.jdiacomp.2014.12.006)

57 Martins C, Kulseng B, King NA, Holst JJ \& Blundell JE. The effects of exercise-induced weight loss on appetite-related peptides and motivation to eat. Journal of Clinical Endocrinology and Metabolism 201095 1609-1616. (doi:10.1210/jc.2009-2082)

58 Zijlstra N, Mars M, de Wijk RA, Westerterp-Plantenga MS, Holst JJ $\&$ de Graaf C. Effect of viscosity on appetite and gastro-intestinal hormones. Physiology \& Behavior 200997 68-75. (doi:10.1016/ j.physbeh.2009.02.001)

Received 13 November 2015

Revised version received 10 March 2016

Accepted 14 March 2016 